\title{
Controversy
}

\section{The 2003 Canadian recommendations for dyslipidemia management: Revisions are needed}

\author{
Douglas G. Manuel, Peter Tanuseputro, Cameron A. Mustard, Susan E. Schultz, \\ Geoffrey M. Anderson, Sten Ardal, David A. Alter, Andreas Laupacis
}

ß See related articles pages 1033 and 1037

$\mathrm{T}$ The recommendations of the 2003 Canadian guidelines for the management and treatment of dyslipidemia, if applied in clinical practice, will result in more people being screened and prescribed statin therapy., When compared with the 2000 guidelines, the 2003 guidelines recommend screening more people with fewer risk factors for coronary artery disease
(CAD) and lower lipid level targets for people in all risk groups (Table 1). We are concerned that these changes will result in hundreds of thousands more people receiving treatment and a marked increase in costs to the Canadian health care system, with small overall improvements to CAD outcomes. Simple revisions to the new guidelines could reduce the number of people receiving treatment

Table 1: Comparison of the recommendations of the 2000 and 2003 Canadian guidelines for the management and treatment of dyslipidemia

\begin{tabular}{|c|c|c|}
\hline Point of comparison & 2000 guidelines & 2003 guidelines \\
\hline $\begin{array}{l}\text { Event used to predict } \\
\text { baseline risk }\end{array}$ & $\begin{array}{l}\text { 10-year risk of CAD-related death or nonfatal } \\
\text { myocardial infarction, unstable angina }\end{array}$ & $\begin{array}{l}\text { 10-year risk of CAD-related death or nonfatal } \\
\text { myocardial infarction }\end{array}$ \\
\hline $\begin{array}{l}\text { Risk factors considered for } \\
\text { risk nomogram }\end{array}$ & $\begin{array}{l}\text { Total cholesterol level, HDL-C level, systolic blood } \\
\text { pressure, age, smoking status }\end{array}$ & $\begin{array}{l}\text { Total cholesterol level, HDL-C level, systolic blood } \\
\text { pressure (considered along with hypertension } \\
\text { treatment status), age, smoking status }\end{array}$ \\
\hline $\begin{array}{l}\text { Who is recommended for } \\
\text { risk assessment? }\end{array}$ & $\begin{array}{l}\text { Men }>40 \text { yr old; women }>50 \text { yr old; adults with } \geq 2 \\
\text { risk factors for CAD; patients with clinical evidence } \\
\text { of CAD, peripheral vascular disease or carotid } \\
\text { atherosclerosis; patients with diabetes; patients with } \\
\text { xanthomata or other stigmata of dyslipidemia; and } \\
\text { patients with a family history of dyslipidemia or CAD }\end{array}$ & $\begin{array}{l}\text { Men > } 40 \text { yr old; women }>50 \text { yr old or } \\
\text { postmenopausal; all patients with diabetes; patients } \\
\text { with risk factors such as hypertension, smoking or } \\
\text { abdominal obesity; patients with a strong family } \\
\text { history of premature cardiovascular disease; patients } \\
\text { with manifestations of hyperlipidemia or evidence of } \\
\text { symptomatic or asymptomatic atherosclerosis }\end{array}$ \\
\hline
\end{tabular}

Definition of risk groups Very high risk (10-year risk of CAD $>30 \%$, or history and target lipid levels

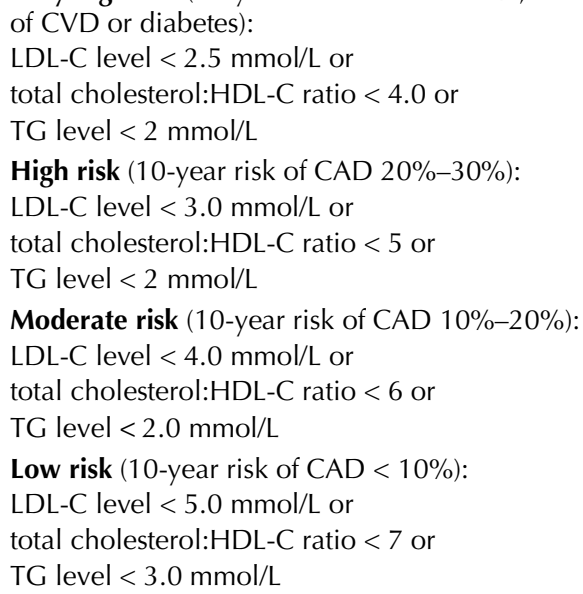

High risk (10-year risk of CAD $\geq 20 \%$, or history of diabetes or any atherosclerotic disease):

LDL-C level $<2.5 \mathrm{mmol} / \mathrm{L}$ and total cholesterol:HDL-C ratio $<4$

Moderate risk (10-year risk of CAD 11\%-19\%):

LDL-C level $<3.5 \mathrm{mmol} / \mathrm{L}$ and

total cholesterol:HDL-C ratio $<5$

Low risk (10-year risk of $\mathrm{CAD} \leq 10 \%)$

LDL-C level $<4.5 \mathrm{mmol} / \mathrm{L}$ and

total cholesterol:HDL-C ratio $<6$ 
and at the same time prevent more CAD-related deaths.

There is no doubt that statins are efficacious. They reduce CAD-related mortality by $15 \%$ to $30 \%{ }^{3,4}$ However, the absolute benefit provided by statins (and the number needed to treat to achieve that benefit) varies enormously, depending on whether patients are at high, medium or low risk of CAD (Table 2). ${ }^{5}$ Under the 2003 recommendations, low-risk patients will be given statin therapy for many years with only a very small reduction in the number of CAD events.

Table 2: Benefit of statin therapy in preventing CAD-related events and deaths by risk group as defined by the 2003 guidelines for the management and treatment of dyslipidemia

\begin{tabular}{|c|c|c|c|c|}
\hline \multirow[b]{2}{*}{ Risk group with patient example } & \multicolumn{2}{|c|}{ "Hard" CAD-related event* } & \multicolumn{2}{|c|}{ CAD-related death } \\
\hline & $\begin{array}{c}\text { 10-year risk, } \\
\%\end{array}$ & $\begin{array}{l}\text { NNT to prevent } 1 \\
\text { event with } 10 \mathrm{yr} \text { of } \\
\text { statin treatment }\end{array}$ & $\begin{array}{l}5 \text {-year risk } \\
\%\end{array}$ & $\begin{array}{l}\text { NNT to prevent } 1 \\
\text { death with } 5 \mathrm{yr} \text { of } \\
\text { statin treatment }\end{array}$ \\
\hline $\begin{array}{l}\text { Low }(10 \text {-yr risk of CAD } \leq 10 \%): 42 \text {-yr-old man with } \\
\text { total cholesterol level of } 6.5 \mathrm{mmol} / \mathrm{L}\end{array}$ & 2 & 210 & 0.05 & 9100 \\
\hline $\begin{array}{l}\text { Medium (10-yr risk of CAD } 11 \%-19 \%): 64-y r-o l d \\
\text { female smoker with total cholesterol level of } 6.5 \\
\mathrm{mmol} / \mathrm{L}, \mathrm{HDL}-\mathrm{C} \text { level of } 0.9 \mathrm{mmol} / \mathrm{L} \text { and untreated } \\
\text { systolic blood pressure of } 160 \mathrm{~mm} \mathrm{Hg}\end{array}$ & 14 & 30 & 2.9 & 150 \\
\hline $\begin{array}{l}\text { High ( } 10 \text {-yr risk of } C A D \geq 20 \% \text { or history of diabetes } \\
\text { mellitus or any atherosclerotic disease): } 70 \text {-yr-old } \\
\text { man with history of heart disease }\end{array}$ & 37 & 11 & 11 & 36 \\
\hline
\end{tabular}

Note: NNT = number needed to treat.

*A "hard" CAD event is CAD-related death or nonfatal myocardial infarction.

Table 3: Analysis of Canadian population in 1992 by risk group using 2000 recommendations for the management of dyslipidemia*†

\begin{tabular}{|c|c|c|c|c|c|c|c|c|c|}
\hline \multirow[b]{2}{*}{ Analysis } & \multirow[b]{2}{*}{ Low risk } & \multirow[b]{2}{*}{ Moderate risk } & \multirow[b]{2}{*}{ High risk } & \multirow[b]{2}{*}{ Very high risk } & \multirow[b]{2}{*}{ Total } & \multirow[b]{2}{*}{$\begin{array}{l}\text { Very high } \\
\text { risk }+ \text { high } \\
\text { risk } \neq\end{array}$} & \multicolumn{3}{|c|}{ Very-high-risk subgroups } \\
\hline & & & & & & & $\begin{array}{l}\text { History } \\
\text { of CVD }\end{array}$ & $\begin{array}{l}\text { History of } \\
\text { diabetes and } \\
\text { age }>30 \mathrm{yr}\end{array}$ & $\begin{array}{l}10-y r \text { risk of } \\
C A D>30 \%\end{array}$ \\
\hline $\begin{array}{l}\text { Estimated no. (\%) of } \\
\text { people }\end{array}$ & $\begin{array}{c}12500000 \\
(78.2)\end{array}$ & $\begin{array}{l}2110000 \\
(13.2)\end{array}$ & $\begin{array}{l}211000 \\
\quad(1.3)\end{array}$ & $\begin{array}{c}1160000 \\
(7.3)\end{array}$ & 16000000 & $\begin{array}{c}1380000 \\
(8.6)\end{array}$ & $\begin{array}{l}499000 \\
(3.1)\end{array}$ & $\begin{array}{l}491000 \\
(3.1)\end{array}$ & $\begin{array}{l}174000 \\
(1.1)\end{array}$ \\
\hline $\begin{array}{l}\% \text { recommended for lipid } \\
\text { testing }\end{array}$ & 38 & 99 & 100 & 100 & 52 & 100 & 100 & 100 & 100 \\
\hline $\begin{array}{l}\text { No. recommended for } \\
\text { statin therapy }\end{array}$ & 61000 & 758000 & 191000 & 986000 & 2000000 & 1180000 & 404000 & 409000 & 173000 \\
\hline $\begin{array}{l}\text { \% recommended for testing } \\
\text { who are subsequently } \\
\text { recommended for treatment }\end{array}$ & 1.3 & 36.1 & 90.2 & 84.7 & 24.2 & 85.6 & 81.1 & 83.2 & 99.4 \\
\hline $\begin{array}{l}\text { NNT to prevent } 1 \text { CAD- } \\
\text { related death with } 5 \mathrm{yr} \text { of } \\
\text { statin therapy }(25 \mathrm{th}-75 \text { th } \\
\text { percentile)§ }\end{array}$ & $\begin{array}{c}2880 \\
(2330-13500)\end{array}$ & $\begin{array}{c}502 \\
(391-1070)\end{array}$ & $\begin{array}{c}142 \\
(119-163)\end{array}$ & $\begin{array}{c}100 \\
(70-282)\end{array}$ & $\begin{array}{c}157 \\
(102-836)\end{array}$ & $\begin{array}{c}105 \\
(76-240)\end{array}$ & $\begin{array}{c}64 \\
(52-99)\end{array}$ & $\begin{array}{c}253 \\
(169-2250)\end{array}$ & $\begin{array}{c}93 \\
(81-122)\end{array}$ \\
\hline $\begin{array}{l}\text { CAD-related deaths } \\
\text { prevented over } 5 \mathrm{yr} \S\end{array}$ & 21 & 1510 & 1340 & 9840 & 12700 & 11200 & 6360 & 1620 & 1850 \\
\hline $\begin{array}{l}\text { Mean probability of CAD- } \\
\text { related death over } 5 \mathrm{yr}, \% \S\end{array}$ & 0.1 & 0.8 & 2.9 & 4.2 & 2.7 & 4.0 & 6.6 & 1.6 & 4.5 \\
\hline $\begin{array}{l}\text { NNT to prevent } 1 \text { "hard" } \\
\text { CAD event with } 10 \mathrm{yr} \text { of } \\
\text { statin therapy ( } 25 \text { th- } 75 \text { th } \\
\text { percentile) }\end{array}$ & $\begin{array}{c}81 \\
(69-139)\end{array}$ & $\begin{array}{c}38 \\
(30-69)\end{array}$ & $\begin{array}{c}21 \\
(19-25)\end{array}$ & $\begin{array}{c}23 \\
(17-54)\end{array}$ & $\begin{array}{c}28 \\
(20-54)\end{array}$ & $\begin{array}{c}23 \\
(17-42)\end{array}$ & $\begin{array}{c}16 \\
(13-20)\end{array}$ & $\begin{array}{c}49 \\
(35-208)\end{array}$ & $\begin{array}{c}19 \\
(17-21)\end{array}$ \\
\hline $\begin{array}{l}\text { "Hard" CAD events } \\
\text { prevented over } 10 \mathrm{yr}\end{array}$ & 754 & 20100 & 9200 & 42200 & 72300 & 51400 & 24900 & 8290 & 9060 \\
\hline $\begin{array}{l}\text { Mean probability of "hard" } \\
\text { CAD event over } 10 \mathrm{yr}, \%\end{array}$ & 5.2 & 11.1 & 20.0 & 17.9 & 15.1 & 18.2 & 25.7 & 8.4 & 21.8 \\
\hline
\end{tabular}

*The reference population is Canadians in 1992 aged 18-74 years. Data from the Canadian Heart Health Survey were used to identify the risk categories of respondents.

tSee Table 1 for risk group definitions.

$\ddagger$ The very-high- and high-risk categories of the 2000 recommendations were combined for comparison with the high-risk category of the 2003 recommendations.

\$Calculated using Framingham study equations ${ }^{7}$ given a $24 \%$ relative efficacy of statins.

I Calculated using risk scoring from the 2003 recommendations given the same $24 \%$ relative efficacy of statins. ${ }^{8}$ 
We used the approach of MacLean and colleagues ${ }^{6}$ and data from the Canadian Heart Health Survey (CHHS) to estimate how the 2003 guideline revisions would affect the Canadian population in terms of the number of people who would be screened and the people for whom treatment with statins would be recommended. Details about the methods are available at www.cmaj.ca/cgi/content/full/172 /8/1027/DC1. In brief, we used CHHS data to identify the proportion of respondents aged 18-74 years who were eligible for screening according to both the 2000 and 2003 guidelines (e.g., respondents who had diabetes, $\mathrm{CAD}$ or 1 or more risk factors for CAD, men older than 40 years, women older than 50 years). Data on the lipid level profile, smoking status and blood pressure of CHHS respondents were also available. Using this information, we determined whether the CHHS respondents were at low, medium or high risk of experiencing a "hard" CAD event (i.e., CADrelated death or nonfatal myocardial infarction) in the next 10 years as determined by the Framingham-based risk point scoring system used in the respective guidelines. Since the Framingham scoring system applies only to people without known cardiovascular disease, we estimated the probability of CHHS respondents with existing cardiovascular disease experiencing a "hard" CAD event using the age-specific 10-year "hard" CAD event rates experienced by an Ontario cohort of patients aged 18-74 who were pre- viously admitted to hospital because of cardiovascular disease between 1988 and 1992. CHHS sampling weights were applied to generate estimates for all Canadians 18-74 years of age.

We then evaluated the health impact of the 2000 and 2003 guidelines on the Canadian population in terms of the number of CAD events potentially prevented and the number needed to treat to prevent a CAD event with statin therapy. The number needed to treat to prevent 1 event was calculated as 1 over the absolute baseline risk of people receiving treatment in each guideline risk group multiplied by the relative effectiveness of statins (assumed to be a constant $24 \%{ }^{3}$ for all risk groups and outcomes). The number needed to treat for some people in the low-risk groups was very large because their baseline risk was extremely low. The guidelines defined the low-risk group as anyone with a 10-year baseline risk of a "hard" CAD event less than $10 \%$ in 2000 and $10 \%$ or less in 2003 . The number of deaths potentially prevented in each risk group was calculated by dividing the total number of people in a risk group by the number needed to treat in that group.

Using the Canadian population aged $18-74$ years in 1992 as the reference population, the number of people for whom statin therapy is recommended increased by $27 \%$, from 2 million using the 2000 guidelines to 2.53 million using the 2003 guidelines (Table 3 and Table 4). Almost all

Table 4: Analysis of Canadian population in 1992 by risk group using 2003 recommendations for the management of dyslipidemia*†

\begin{tabular}{|c|c|c|c|c|c|c|c|}
\hline \multirow[b]{2}{*}{ Analysis } & \multirow[b]{2}{*}{ Low risk } & \multirow[b]{2}{*}{ Moderate risk } & \multirow[b]{2}{*}{ High risk $\neq$} & \multirow[b]{2}{*}{ Total } & \multicolumn{3}{|c|}{ High-risk subgroups } \\
\hline & & & & & $\begin{array}{l}\text { History of } \\
\text { CVD }\end{array}$ & $\begin{array}{c}\text { History of } \\
\text { diabetes and age } \\
>30 \mathrm{yr}\end{array}$ & $\begin{array}{l}10-y r \text { risk of } \\
\text { CAD }>30 \%\end{array}$ \\
\hline Estimated no. (\%) of people & $\begin{array}{c}13400000 \\
(83.8)\end{array}$ & $\begin{array}{c}1040000 \\
(6.5)\end{array}$ & $\begin{array}{c}1543000 \\
(9.7)\end{array}$ & 16000000 & $\begin{array}{l}499000 \\
(3.1)\end{array}$ & $\begin{array}{l}491000 \\
\quad(3.5)\end{array}$ & $\begin{array}{l}553000 \\
(3.5)\end{array}$ \\
\hline $\begin{array}{l}\% \text { recommended for lipid } \\
\text { testing }\end{array}$ & 72 & 100 & 100 & 76 & 100 & 100 & 100 \\
\hline $\begin{array}{l}\text { No. recommended for statin } \\
\text { therapy }\end{array}$ & 595000 & 585000 & 1350000 & 2530000 & 404000 & 409000 & 534000 \\
\hline $\begin{array}{l}\text { \% recommended for testing who } \\
\text { are subsequently recommended } \\
\text { for treatment }\end{array}$ & 6.2 & 56.2 & 87.3 & 20.7 & 81.1 & 83.2 & 96.5 \\
\hline $\begin{array}{l}\text { NNT to prevent } 1 \text { CAD-related } \\
\text { death over } 5 \mathrm{yr} \text { of statin therapy } \\
\text { (25th-75th percentile)§ }\end{array}$ & $\begin{array}{c}1550 \\
(1031-19600)\end{array}$ & $\begin{array}{c}366 \\
(270-975)\end{array}$ & $\begin{array}{c}117 \\
(80-394)\end{array}$ & $\begin{array}{c}187 \\
(130-1805)\end{array}$ & $\begin{array}{c}64 \\
(52-99)\end{array}$ & $\begin{array}{c}253 \\
(169-2250)\end{array}$ & $\begin{array}{c}151 \\
(116-333)\end{array}$ \\
\hline $\begin{array}{l}\text { CAD-related deaths prevented } \\
\text { over } 5 \mathrm{yr} \S\end{array}$ & 384 & 1600 & 11500 & 13500 & 6360 & 1620 & 3520 \\
\hline $\begin{array}{l}\text { Mean probability of CAD-related } \\
\text { death over } 5 \mathrm{yr}, \% \S\end{array}$ & 0.3 & 1.1 & 3.6 & 2.2 & 6.6 & 1.6 & 2.8 \\
\hline $\begin{array}{l}\text { NNT to prevent } 1 \text { "hard" CAD } \\
\text { event over } 10 \mathrm{yr} \text { of statin } \\
\text { therapy ( } 25 \text { th-75th percentile) }\end{array}$ & $\begin{array}{c}91 \\
(69-208)\end{array}$ & $\begin{array}{c}31 \\
(26-35)\end{array}$ & $\begin{array}{c}22 \\
(17-30)\end{array}$ & $\begin{array}{c}29 \\
(21-69)\end{array}$ & $\begin{array}{c}16 \\
(13-20)\end{array}$ & $\begin{array}{c}49 \\
(35-208)\end{array}$ & $\begin{array}{c}18 \\
(17-21)\end{array}$ \\
\hline $\begin{array}{l}\text { "Hard" CAD events prevented } \\
\text { over } 10 \mathrm{yr} \uparrow\end{array}$ & 6550 & 19100 & 62400 & 88100 & 24900 & 8360 & 29200 \\
\hline $\begin{array}{l}\text { Mean probability of "hard" CAD } \\
\text { event over } 10 \mathrm{yr}, \% \text { q }\end{array}$ & 4.6 & 13.6 & 19.3 & 14.5 & 25.7 & 8.5 & 22.8 \\
\hline
\end{tabular}

*The reference population is Canadians in 1992 aged 18-74 years. Data from the Canadian Heart Health Survey were used to identify the risk categories of respondents.

†See Table 1 for risk group definitions.

¥The very-high- and high-risk categories of the 2000 recommendations were combined for comparison with the high-risk category of the 2003 recommendations.

§Calculated using Framingham study equations ${ }^{7}$ given a $24 \%$ relative efficacy of statins. ${ }^{8}$

I Calculated using risk scoring from the 2003 recommendations given the same $24 \%$ relative efficacy of statins. 
of the increase consisted of patients in the low-risk category. The number of low-risk people for whom statins are recommended if lifestyle modification fails to achieve target lipid levels increased 10-fold, from 61000 to 595000 . Yet, the relative benefit of statin therapy for many people in the low-risk group is incredibly small. By our estimates, among the 149000 Canadians who fall within the highestrisk quartile in this group, the number needed to treat with 5 years of statin therapy to prevent $1 \mathrm{CAD}$-related death would be 19600 . The number needed to treat to prevent 1 CAD-related death in the low-risk group recommended for statin therapy ( $n=595000)$ would be 1550 .

Conversely, according to CHHS data, about $12.5 \%$ (193 000/1 543 000) (Table 4) of high-risk people have low-density lipoprotein cholesterol levels below the recommended target. According to the 2003 guidelines, these people would not be recommended for statin treatment. However, the Heart Protection Study ${ }^{4}$ is widely cited as providing evidence for the benefit of statin therapy for most of these people. The 2003 guidelines acknowledge the evidence of this and other studies. In our estimate, the number needed to treat for 5 years to prevent 1 death is 10 times more favourable for high-risk people currently not recommended therapy than for low-risk people who are recommended therapy (141 v. 1550).

By these calculations, if the 2003 guidelines were modi- fied to recommend statins for all high-risk people and no low-risk people, 1010 more deaths over 5 years might be prevented and 398000 fewer people $(2.5 \%$ of the total population) given treatment. Although the guidelines recommend screening the entire adult population, in practice not everyone will be screened or offered treatment or will persist on statin therapy. Thus, the actual impact in terms of the potential number of deaths prevented or people treated would be considerably lower..$^{9-13}$

In Canada, statin prescriptions increased over 3 -fold between 1996 and 2000 to 11 million prescriptions at a cost of $\$ 1.1$ billion annually. ${ }^{11}$ The further $27 \%$ increase incurred if the revised recommendations are followed would contribute an additional $\$ 250$ million in drug costs each year. On the other hand, recommending statins for all high-risk people and no low-risk people, using the 2003 definitions for the risk groups, would reduce the number of people recommended statins by $16 \%$ and avoid more deaths (Fig. 1). The New Zealand approach of recommending treatment for all people with a history of CAD or a 10 -year risk of CAD-related death greater than $15 \%^{14}$ is even more efficient. Applying the New Zealand guidelines in Canada would result in the prevention of slightly more CAD-related deaths, treatment of $37 \%$ fewer people and savings of $\$ 100$ million compared with using the revised 2003 guidelines (Fig. 1). ${ }^{14}$

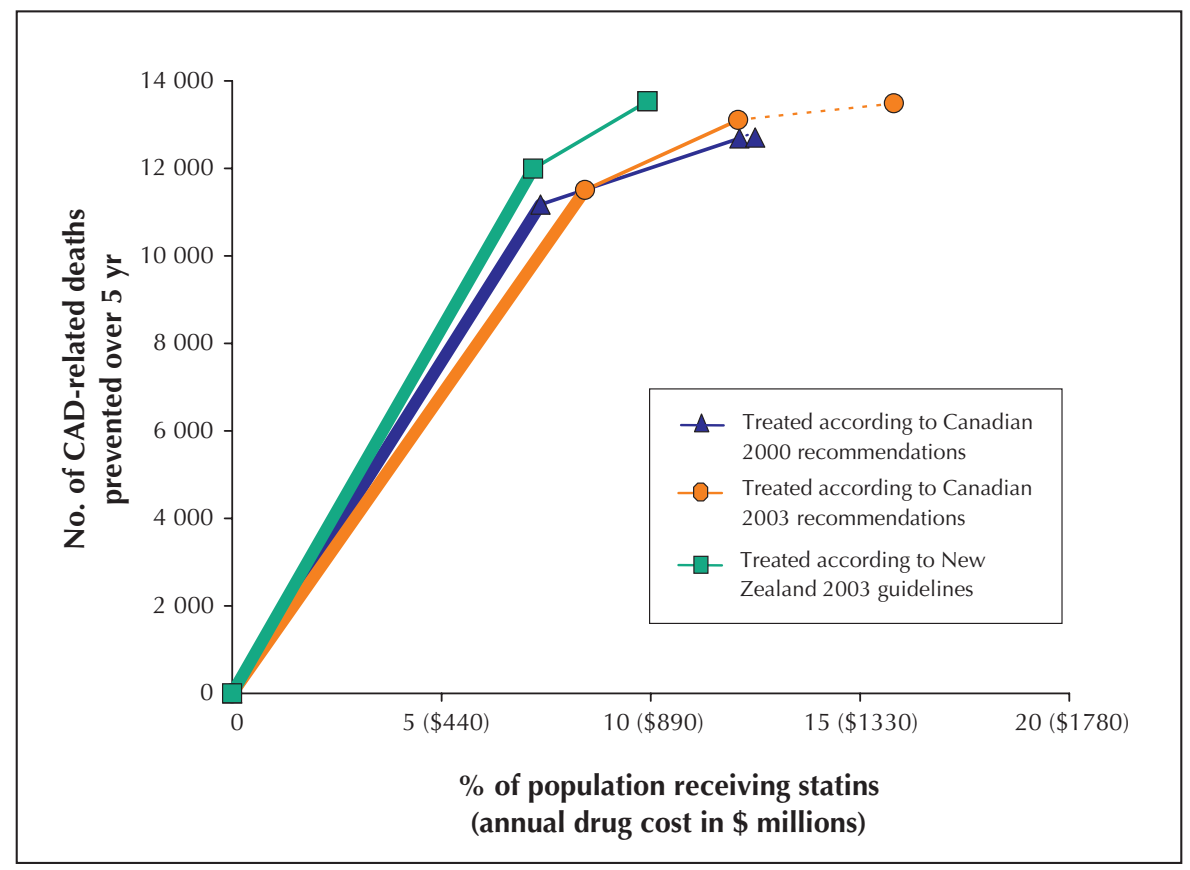

Fig. 1: No. of deaths from coronary artery disease (CAD) prevented over 5 years among people aged 18-74 years receiving statin therapy according to the 2000 and 2003 Canadian recommendations and the 2003 New Zealand guidelines. This assumes that all eligible people were screened and were compliant with the statin therapy recommended and that the drug cost was $\$ \mathbf{1 . 5 2}$ per day. Thick solid rules represent people at high risk for CAD, thinner solid rules represent people at moderate risk, and dotted rules represent people at low risk; for the 2000 Canadian recommendations, the categories of high and very high risk have been combined. 
These calculations have implications for patients, clinicians, funding agencies and those interested in population health. Fully informed patients are often less aggressive about therapy than their clinicians. ${ }^{15}$ As well, low-risk patients will paradoxically sometimes receive more aggressive treatment than high-risk patients. ${ }^{13,16}$ The very small absolute benefits associated with statin therapy in low-risk patients highlights the importance of informing these patients about the absolute benefits and risks of statins. Our analysis reinforces the importance of ensuring that clinicians offer statin therapy to high-risk patients, since they are the patients with the most to gain. Even high-risk patients whose low-density lipoprotein cholesterol levels are below the target given in the 2003 guidelines should be considered for statin therapy.

It is important to remember that a drug that is efficacious in high-risk patients is also typically efficacious in very-low-risk patients, but the absolute benefits and costeffectiveness are almost always lower. Costs for the individual (including costs related to the drug, testing, doctor and clinic visits, being labeled as "sick" or carrying a risk factor) and for society (drug and treatment costs) suggest that the funds spent on statins for low-risk patients may be better used elsewhere. Including information on the absolute benefits and cost-effectiveness of statin therapy in dyslipidemia guidelines - as New Zealand and European guidelines $\mathrm{do}^{14,17}$ - allows for more meaningful discussions about who should receive the therapy. Our analysis demonstrates that estimating absolute benefit can improve guidelines by more clearly identifying who will benefit most from statins. Since there is no clear threshold of benefit or cost-effectiveness of statins, societal views should be elicited before expanding recommendations to a large number of low-risk people. The editors and reviewers of CMAJ should call on guideline authors to include measures of absolute benefit and to address resource implications of recommendations that are published in the journal. ${ }^{18} \mathrm{We}$ urge the authors of the Canadian dyslipidemia guidelines to consider our analysis and revise their recommendations.

From the Institute for Clinical Evaluative Sciences (Manuel, Tanuseputro, Schultz, Anderson, Alter, Laupacis), the Department of Public Health Sciences, University of Toronto (Manuel, Mustard), the Institute for Work and Health (Mustard), the Department of Health Policy, Management and Evaluation, University of Toronto (Anderson, Laupacis), the Central East Health Information Partnership (Ardal), the Division of Cardiology, Schulich Heart Centre (Alter), the Department of General Internal Medicine, Sunnybrook \& Women's College Health Sciences Centre and the University of Toronto (Laupacis), and the Clinical Epidemiology and Health Care Research Program (Sunnybrook \& Women's College site) (Laupacis), Toronto, Ont.

\section{Competing interests: None declared.}

Contributors: Douglas Manuel was the primary author and was responsible for the design of the study and the analysis and interpretation of the data. All authors provided advice and assistance for the initial design of the study. Peter Tanuspetro and Susan Schultz performed the analysis. All authors participated in revising the manuscript and approved the final version for submission.
Acknowledgements: We thank Jenny Lim for her contribution to the additional analysis and assistance in preparing the manuscript.

Douglas Manuel is a Career Scientist with the Ontario Ministry of Health and Long-Term Care. David Alter holds a New Investigator Award from the Canadian Institutes of Health Research and the Heart and Stroke Foundation of Canada. Cameron Mustard held an Investigator Award from 1999 to 2003, and Andreas Laupacis holds a Senior Scientist Award from the Canadian Institutes of Health Research. Support for this project was received from the Canadian Population Health Initiative. The opinions expressed are those of the authors and not necessarily those of the institutions with which they are affiliated.

\section{References}

1. Fodor JG, Frohlich JJ, Genest JJ, Jr., McPherson PR. Recommendations for the management and treatment of dyslipidemia. Report of the Working Group on Hypercholesterolemia and Other Dyslipidemias. CMAJ 2000;162 (10):1441-7.

2. Genest J, Frohlich J, Fodor G, McPherson R (the Working Group on Hypercholesterolemia and Other Dyslipidemias). Recommendations for the management of dyslipidemia and the prevention of cardiovascular disease: summary of the 2003 update. CMA7 2003;169(9):921-4.

3. LaRosa JC, He J, Vupputuri S. Effect of statins on risk of coronary disease: a meta-analysis of randomized controlled trials. FAMA 1999;282(24):2340-6.

4. MRC/BHF Heart Protection Study of cholesterol lowering with simvastatin in 20,536 high-risk individuals: a randomised placebo-controlled trial. Lancet 2002;360(9326):7-22.

5. Alter DA, Manuel DG, Gunraj N, Anderson G, Naylor CD, Laupacis A. Age, risk-benefit trade-offs, and the projected effects of evidence-based therapies. Am 7 Med 2004;116(8):540-5.

6. MacLean DR, Petrasovits A, Connelly PW, Little JA, O'Connor B. Impact of different blood lipid evaluation and treatment guidelines on the proportion of Canadians identified and treated for elevated blood cholesterol. Canadian Heart Health Surveys Research Group. Can 7 Cardiol 1999;15(4):445-51.

7. Anderson KM, Odell PM, Wilson PW, Kannel WB. Cardiovascular disease risk profiles. Am Heart 7 1991;121:293-8.

8. Prevention of cardiovascular events and death with pravastatin in patients with coronary heart disease and a broad range of initial cholesterol levels. The Long-Term Intervention with Pravastatin in Ischaemic Disease (LIPID) Study Group. N Engl 7 Med 1998;339:1349-57.

9. Alzahrani T, Marrat S, Haider A. Management of dyslipidemia in primary care. Can 7 Cardiol 2003;19(13):1499-502.

10. Jackevicius CA, Mamdani M, Tu JV. Adherence with statin therapy in elderly patients with and without acute coronary syndromes. 7AMA 2002;288(4):462-7.

11. Jackevicius CA, Tu K, Filate WA, Brien SE, Tu JV. Trends in cardiovascular drug utilization and drug expenditures in Canada between 1996 and 2001. Can 7 Cardiol 2003;19(12):1359-66.

12. Benner JS, Glynn RJ, Mogun H, Neumann PJ, Weinstein MC, Avorn J. Long-term persistence in use of statin therapy in elderly patients. $7 A M A$ $2002 ; 288(4): 455-61$.

13. Ko DT, Mamdani M, Alter DA. Lipid-lowering therapy with statins in highrisk elderly patients: the treatment-risk paradox. FAMA 2004;291(15):1864-70.

14. New Zealand Guidelines Group. The assessment and management of cardiovascular risk. December 2003. Wellington, New Zealand. Available: www.nzgg .org.nz/index.cfm?fuseaction=fuseaction_10\&fusesubaction=docs\&documentID $=22($ accessed 09 Mar 05).

15. McAlister FA, O'Connor AM, Wells G, Grover SA, Laupacis A. When should hypertension be treated? The different perspectives of Canadian family physicians and patients. CMA7 2000;163(4):403-8.

16. Rutten FH, Hak E, Stalman WA, Verheij TJ, Hoes AW. Is treatment of atrial fibrillation in primary care based on thromboembolic risk assessment? Fam Pract 2003;20(1):16-21.

17. De Backer G, Ambrosioni E, Borch-Johnsen K, Brotons C, Cifkova R, Dallongeville J, et al. European guidelines on cardiovascular disease prevention in clinical practice. Third Joint Task Force of European and Other Societies on Cardiovascular Disease Prevention in Clinical Practice. Eur Heart 7 2003;24 (17):1601-10.

18. Laupacis A. Osteoporosis guidelines [letter]. CMA7 2003;168(13):1644-5.

Correspondence to: Dr. Douglas G. Manuel, Institute for Clinical Evaluative Sciences, Rm. G106, 2075 Bayview Ave., Toronto ON M4N 3M5; fax 416 480-6048; doug.manuel@ices.on.ca 